\section{Specificity of carbachol in the elicitation of drinking*}

\author{
LARRY R. BEIDEMAN' and ROBERT GOLDSTEIN \\ Washington University, St. Louis, Mo. 63104
}

Two studies were reported in which rats with hypothalamic cannulae were injected with carbachol. All animals exhibited drinking following injection. In the first study, this was demonstrated both prior to and following a series of test sessions, and in the second study, at the end only. During the test sessions themselves, only food was available. Animals displayed no tendency to increase their food intake upon carbachol administration during the 16 test sessions. This was contrasted with the ease with which such shifts have been demonstrated with electrical stimulation and suggests a specificity of function that can be detected with chemical but not electrical stimulation.

It is a well-documented fact that electrical or chemical stimulation of hypothalamic sites can produce consummatory behavior. The most common explanation of this phenomenon is that the stimulation energizes motivational mechanisms that are normally involved in the mediation of these responses. Areas from which feeding can be evoked by stimulation, accordingly, are conceived of as active under conditions of normal deprivation, and this activity represents the neural concommitant of hunger. Valenstein, Cox, \& Kakolewski (1969) have described a series of recent studies from which they have concluded, on the contrary, that these responses are not reflections of normal motivational states but instead constitute the discharge of sensitized neural substrates "... underlying well-established response patterns [p. 29]." One source for this conclusion is the fact that the various evokable responses seem to be, in a great degree, modifiable. Thus, given the proper conditions, Ss who show one response upon stimulation can almost invariably be induced to perform at least one or more other responses that compete favorably with the initial behavior in subsequent stimulation tests.

This response plasticity during electrical stimulation stands in apparent contrast to the specificity of behavior elicited by chemical stimulation (Grossman, $1962 a, b)$. The question to which the present study is addressed is whether or not the response elicited by chemical stimulation can be subjected to the same manipulations as Valenstein has demonstrated to be effective with electrical stimulation.

\section{SERIES A \\ Subjects and Apparatus}

The Ss were nine male albino rats approximately 160 days old at the time of operation. They were housed individually throughout the experiment in a series of saline and handling control tests. (All tests during and after this series were conducted on alternate days; the designation "days" will hereafter imply test days rather than consecutive days.) On the first five of these control days, each animal was taken out of its cage and injected with 1 microliter of physiological saline. On the following 4 days, each animal was handled for an equivalent time period but was not injected. Food and water levels were recorded prior to injection or handling. After the appropriate manipulations, the $S$ was returned to its compartment and water intake was recorded after delays of 15,30 , and $60 \mathrm{~min}$; food intake was recorded at 30 and $60 \mathrm{~min}$ only. This procedure was continued throughout the following drug tests.

Upon completion of the control phase, the Ss underwent a series of 17 injection days on each of which 1 microliter of $0.8 \mathrm{micrograms} / \mathrm{microliter}$ of carbachol (carbamylcholine chloride) was injected. The goal objects available to the rats followed a sequence similar to that employed by Valenstein, Cox, \& Kakolewskj (1968a) for electrical stimulation. That is, on the first day, food; water, and gnawing block were all avaiiabie. Since drinking was the only response observed during the first stimulation test, the water was removed following the next 15 injections and replaced 15-30 min after each test hour. Food intake was recorded as usual, and gnawing, if any, was noted. On the 17th test day water was once more available along with the food and wood block.

\section{Results}

For data analysis the total food and water intakes in the test hours were employed, although the carbachol effect usually terminated within $30-40 \mathrm{~min}$. No gnawing was observed throughout the experiment.

The first point necessary to ascertain was whether the individual Ss displayed consummatory behavior upon stimulation. This was established by comparing the food and water intake following injection to the baseline intakes in the control tests. (Since there was no differential effect on intake of handling alone compared to handling plus saline injection, the data for these 9 control days were pooled.) A mean and standard deviation were calculated for each rat's food intake and another for each rat's water intake on the control days. The food and water intakes of each $S$ on the first carbachol day were then expressed as deviation scores from its own control means. In these terms, every rat demonstrated a significant increase in water intake $(p<.01$ in every case) 
whereas none showed an increase in food consumption ( $p>.05$ for every $S)$. For the group as a whole, the water intake increased from $3.9 \mathrm{ml}$ under control conditions to $13.6 \mathrm{ml}$ in the hour following carbachol injection.

Following carbachol administration on the subsequent food-only days, every animal showed a somewhat reduced food intake. On the final carbachol day (food and water both available), the food and water intakes were essentially the same as on the initial carbachol day. Thus, carbachol increased water intake but did not induce feeding despite repeated exposure to food in the absence of water. SERIES B

As Valenstein, Cox, \& Kakolewski (1970) have indicated, the amount of experience an animal has had with a goal object can play a role in the preference subsequently displayed for that object. In the present context it is conceivable that the exposure to water on the first carbachol test might have biased the probability that feeding would emerge in the succeeding tests. This was controlled for in a second series. Ss were four male albino rats approximately 160 days old at the time of operation. The apparatus, surgery, and procedure were identical to those in Series A with the single exception that the first carbachol day was omitted (when both water and food were presented in the first series). Thus, the last day of this series was the first on which water as well as food was available after carbachol injection.

Some time after the second series was completed, all Ss were sacrificed, then perfused with isotonic saline and formalin Cannula localization was accomplished, following slicing, by microscopic examination of the unstained sections (100 microns).

\section{Results}

The data of Series B were treated in the same manner as that of the first series and with the same results. The water intake of each $S$ in the final carbachol test was significantly greater than on its precarbachol control days $(\mathrm{p}<.01$ in every case). The food intake of individual rats on the last 5 food-only days again revealed a universal reduction compared to baseline consumption. Thus, every animal in both series showed a reduction in food intake upon carbachol injection. In fact, this inhibition was statistically significant in five of the nine Ss ( $p<.05$ in each case).

The histological results verified the assumption that the inner cannula in all cases extended into the target area. In the DeGroot (1959) system this corresponded to 4.8 to $5.2 \mathrm{~A}, 1.8$ to 2.2 laterally, and approximately -2.3 in the horizontal plane.

\section{DISCUSSION}

The results support the hypothesis of a functional chemical specificity in the rat hypothalamus for drinking behavior. For both groups of animals, carbachol evoked drinking upon the first test exposure to water. Nevertheless, repeated injections of carbachol in the absence of water did not elicit eating or gnawing responses, whether or not the first drinking test preceded or followed the eating/gnawing tests. The contrasting ease of transition from stimulus-bound drinking to stimulusbound eating with electrical stimulation suggests that we are dealing here with a different order of events. In fact, the present evidence suggesting that food intake is depressed by carbachol is reminiscent of the reduction in eating commonly observed during normal thirst (e.g., Kutscher, 1969). Also suggestive of normal thirst was the fact that two animals given carbachol subsequent to the second series drank as readily from a dish of water as they had previously from the tube. Again by way of contrast, stimulus-bound eating (Valenstein, Cox, \& Kakolewski, $1968 \mathrm{~b}$ ) and drinking (Valenstein, Kakolewski, \& Cox, 1968a) induced by electrical stimulation do not generalize along a dimension indicative of an underlying need.

With respect to the suggestion (Valenstein et al, 1970) that chemical stimulation might exert its effect by potentiating responses that already have a high probability (such as drinking in the rat) rather than evoking these responses, the selective nature of the chemical would still remain as a problem to resolve. Recent data by Smith, King, \& Hoebel (1970), furthermore, would seem to argue against this alternative. In addition to its pertinence in this regard, the latter's evidence also serves as a partial response to the challenge issued by Valenstein et al (1970) to extend the concept of specific pharmacological coding "... to include a similar coding of the neural circuits underlying gnawing, copulation, grooming, stalking-attack ..." (p. 24). It should be mentioned that Smith et al also observed eating by their carbachol-injected animals, a fact that would appear to necessitate some qualification of a strict specificity notion. However, the long latency to first kill, the absence of drinking in their study, and the differences in injection parameters (dose size and form) suggest caution in directly analogizing their results to those reported here.

! Gven that the interpretation of chemically evoked responses is not whout its controversies (Routtenberg, 1967; Fisher \& Levitt, 1967), one should hasten to add that electrical excitation is by no means a physiological stimulus. Moreover, if we assume the existence of interlaced but nevertheless specific circuits, the problem of predicting the response to simultaneous activation of these circuits becomes paramount. Thus, where under normal circumstances thirst and hunger are reciprocally related, electrical stimulation evokes both states (and possibly others as well) simultaneously. Under these circumstances it would be surprising if the evoked consummatory responses mimicked the normally elicited behavior in all respects.

\section{REFERENCES}

DeGROOT, J. The rat forebrain in stereotaxic coordinates. Verh. K. ned. Akad. Wet., B. Naturkunde, 1959, 52, 1-40.

FISHER, A. E., \& LEVITT, R. A. A reply to Routtenberg, Science, 1967, 157, 839-841.

GOLDSTEIN, R. A method to reduce dislodgment of implanted cranial electrodes in rats. Technical note. Journal of the Experimental Analysis of Behavior, 1967, 10 , 290.

GROSSMAN, S. P. Direct adrenergic and cholinergic stimulation of hypothalamic mechanisms. American Journal of Physiology, 1962a, 202, 872-882.

GROSSMAN, S. P. Effects of adrenergic and cholinergic blocking agents on hypothalamic mechanisms. American Journal of Physiology, $1962 \mathrm{~b}, 202,1230-1236$

KUTSCHER, C. Some physiological correlates of adaptation to a water deprivation schedule. In M. Wayner (Ed.), Thirst. New York: Pergamon Press, 1969. Pp. 257-267.

ROUTTENBERG, A. Drinking induced by carbachol: Thirst circuit or ventricular modification. Science, 1967, 157, 838-839.

VALENSTEIN, E. S., COX, V. C., \& KAKOLEWSKI, J. W. Modification of motivated behavior elicited by electrical stimulation of the hypothalamus. Science, 1968a, 159, 1119-1121.

VALENSTEIN, E. S., COX, v. C., \& KAKOLEWSKl, J. W. The motivation underlying eating elicited by lateral hypothalamic stimulation. Physiology \& Behavior, 1968b, 3, 969-971.

VALENSTEIN, E. S., COX, V. C., \& KAKOLEWSKI, J. W. The hypothalamus and motivated behavior. In J. Tapp (Ed.) Reinforcement. New York: Academic Press, 1969. Pp. 242-285.

VALENSTEIN, E. S., COX, V. C., \& KAKOLEWSKI, J. W. Reexamination of the role of the hypothalamus in motivation. Psychological Review, 1970, 77, 16-31.

VALENSTEIN, E. S., KAKOLEWSKI, J. W., \& COX, V. C. A comparison of stimulus-bound drinking and drinking induced by water deprivation. Communications in Behavioral Biology, 1968, 2, 227-23.

SMITH, D. E., KING, M. B., \& HOEBEL, B. G. Lateral hypothalamic control of killing Evidence for a cholinoceptive mechanism. Science, 1970, 167, 900-901.

*This research was conducted at the Washington University Behavioral Research facility at Malcolm Bliss Mental Health Center in St. Louis and was supported, in part, by USPHS Grant MH7081.

tAddress correspondence to the Behavior Research Laboratories, Malcolm Bliss Mental Health Center. 1420 Grattan St., St. Louis, Mo. 63104. 